\title{
A systematic review of infliximab in the treatment of early rheumatoid arthritis
}

\author{
Sophie Martin Du Pan \\ Cem Gabay \\ Axel Finckh \\ Division of Rheumatology, \\ Department of Internal Medicine, \\ University of Geneva
}

Correspondence:Axel Finckh

Division of Rheumatology, University

Hospital of Geneva,Av. Beau-Séjour 26,

$\mathrm{CH}$ I2I I Geneva I4, Switzerland

$\mathrm{Tel}+4 \mathrm{I} 223823693$

Fax +4I 223823530

Email:axel.finckh@hcuge.ch
Background: Several health authorities have recently revised the indication of infliximab (IFX) to include the treatment of early rheumatoid arthritis (RA). The aim of this systematic review of the literature was to appraise the efficacy, safety, and cost-effectiveness of early therapy with IFX.

Methods: We identified published clinical trials from 1966 to May 2006. We included randomized clinical trials (RCTs) in RA with disease duration of less than 3 years comparing the treatment of methotrexate-IFX (MTX-IFX) with methotrexate-placebo (MTX-placebo).

Results: A total of 8 studies met inclusion criteria. Three studies reported redundant data regarding the vdH Sharp Score. Out of the 5 remaining studies, 4 analyzed structural joint destruction (vdH Sharp Score) and demonstrated a significant reduction in radiographic damage progression in favor of the combination of MTX-IFX compared with MTX-placebo $(-4.1 \mathrm{vdH}$ Sharp Score units (95\% CI: 3.5; 4.6). Three studies also displayed a benefit of MTX-IFX on functional outcomes of RA (HAQ score) and disease activity measures (DAS, ACR response criteria), although less markedly.

Conclusions: Although data might be skewed because of only 2 existing large studies with concordant data, results from RCTs demonstrate improved efficacy of the combination MTXIFX compared with MTX-placebo in early RA. However, many early RA patients probably do not require the addition of IFX to achieve a satisfying clinical and radiological course. So far, no evidence has established the superiority of MTX-IFX over MTX-prednisone or other combinations of traditional disease-modifying anti-rheumatic agents.

Keywords: rheumatoid arthritis, antirheumatic agents, infliximab

\section{Introduction}

Rheumatoid arthritis (RA) is a chronic inflammatory disease associated with progressive irreversible joint damage and major permanent disability. Rheumatoid arthritis is the most common systemic rheumatic disease, affecting approximately $1 \%$ of the adult population, with a maximum incidence between ages 35 to 55 (Silman 2001). Its overall economic consequences for society are comparable with that of coronary artery disease (Callahan 1998) and its impact on individuals is considerable, as the disease leads to progressive restricted joint mobility, pain, and functional disability. The disease's relatively early onset in life means that it affects the working-age population, resulting in a work disability rate 10 times higher than an age- and sexmatched population with enormous indirect costs due to lost productivity (Felts et al 1989). Two years after diagnosis, $20 \%$ of RA patients stop their professional activity and more than 50\% will be work-disabled after 10 years of disease (Young et al 2002). Rheumatoid arthritis also increases mortality, with survival similar to that of patients with lymphoma or severe ischemic heart disease (Pincus 1998).

The treatment of RA is still unsatisfactory, but a number of new and more powerful disease-modifying antirheumatic drugs (DMARDs) have become available, such 
as anti-TNF agents, B-cell depleting agents, or selective costimulation inhibitors. Until 15 years ago, the recommended therapeutic strategy was to start with non-steroidal anti-inflammatory drugs (NSAIDs) or low-dose glucocorticoids, and only if these were insufficient to control the disease, more potent antirheumatic therapies were progressively introduced (pyramid approach). In the past 15 years, treatment goals have evolved from "symptom-control" to a broader concept of "disease control" (Edmonds et al 1993). Controlling joint destruction has become the major objective for treating RA (ACR 2002), because radiographic joint damage correlates strongly with long-term functional decline in RA patients (Scott et al 2003). Key agents in this strategy are DMARDs, which have been shown to control progressive structural joint damage. These therapies improve morbidity and mortality in RA and increase quality-adjusted life expectancy to an extent similar to the effects of adjuvant chemotherapy for metastatic breast cancer or beta-blocker therapy for patients at moderate risk of recurrent myocardial infarction (Barbieri et al 2005).

Recent changes in RA treatment paradigms have resulted in a more aggressive therapeutic approach (Wilske et al 1989), with initiation of antirheumatic drugs before significant structural joint occurs. The rationale for a prompt initiation of DMARDs in early RA is based on the "window of opportunity" paradigm. The early stages of the disease appears to be a critical period for the treatment of RA; treatments early are more effective than later in the course of the disease and might permanently modify the disease to a milder course (Combe et al 2006; Finckh et al 2006). Nevertheless, health authorities, in most countries still limit the use of the more expensive biologic agents to patients who have failed one or several traditional DMARDs, which effectively eliminates these agents from the management of early RA. Recently, however, health authorities in several countries have revised the indication of infliximab (IFX) to include the treatment of early RA (Schering-Plough 2006).

To appraise the efficacy, safety, and cost-effectiveness of early therapy with IFX, we conducted a systematic review of the literature and performed a meta-analysis of the RA bone erosion score (vdH Sharp Score) and RA functional disability score (HAQ)

\section{Methods}

\section{Search strategy}

We identified all studies in any language on therapy with IFX in early RA by a systematic search of the literature and electronic databases, including MEDLINE (1966-May 2006),
EMBASE (1974-May 2006), and the Cochrane controlled trial registry. We also reviewed abstracts from the American College of Rheumatology (ACR) and the European League Against Rheumatism scientific meetings from 2004 through 2005 and contacted companies producing IFX (Essex and Centocor) for unpublished data. Search terms were: "Rheumatoid arthritis" OR "arthritis", AND “early", AND "randomized controlled trial". We searched for additional studies by scrutinizing bibliographies of articles.

Study inclusion criteria were:

- Subjects diagnosed with RA using ACR criteria (Arnett et al 1988)

- Disease duration less than 3 years ("early RA").

- Randomized controlled trials (RCT)

Exclusion criteria:

- Duplicate data

\section{Statistical analysis}

A meta-analysis of the radiographic data was performed using the van der Heijde-Sharp (vdH-S) score, reported in most studies. We computed the mean difference in change scores between the two treatment groups and computed the standard deviation of the change score by assuming unpaired data (Deeks et al 2004). All analyses were performed with STATA version 9.2 meta-analysis routines. We used fixed effects models with an $\alpha$-error of 0.05 .

\section{Results}

Seventeen original studies were identified using our bibliographic search criteria, of which 8 abstracts corresponded to our inclusion criteria. The 9 remaining dealt either with other rheumatological conditions (ankylosing spondylitis, psoriasic arthritis) or with fundamental research. For the meta-analysis of vdH-S score, 3 of the 7 studies reporting joint destruction were excluded (duplicate data), 2 of which used the ASPIRE data (Smolen et al 2006a, 2006b) and the third used the same patients as in Taylor et al (2004).

\section{Disease activity}

In RA, disease activity and response to therapy are generally assessed with composite scores, which incorporate clinical assessment parameters, the acute phase reactants (erythrocyte sedimentation rate [ESR] or C-reactive protein [CRP]) and patient data. The ACR response criteria include a tender and swollen joint count, a patient's and the physician's global assessment, acute phase reactants, a pain scale, and a functional questionnaire. An ACR response of 20, 50, and 70 reflects an improvement in several of these measures of at least $20 \%$, 
$50 \%$, and 70\% respectively (Felson et al 1995). The disease activity score (DAS 28) is a composite score including the swollen joint count, the tender joint count, the ESR, and the patient's global assessment. The DAS ranges from 0 to 10 , 0 representing no disease activity and 10 a maximum. Both composite measures correlate reasonably well with short-term structural damage and employability (Graudal et al 2000; Jansen et al 2001; Combe et al 2006). The largest double blind RCT, the ASPIRE trial (St Clair et al 2004), included 1049 patients, and compared the effect of methotrexate-IFX (MTX-IFX) with MTX-placebo on clinical, radiological, and functional scores at 1 year. Patients were randomized in 1 of 3 treatment strategies: MTX-IFX 3 mg/kg, MTX-IFX 6 mg/kg, or MTX-placebo. A statistically significant difference in the ACR 20, 50, and 70 scores was demonstrated at 1 year in favor of the MTX-IFX regimen, but statistically significant advantages in the DAS 28 score were observed only in the highest IFX dosage group. At 1 year, depending on the IFX doses, $62 \%-66 \%$ of patients reached an ACR 20 response in the MTX-IFX combination group compared with 53\% in the MTX-placebo group; $45 \%-50 \%$ reached an ACR 50 in the MTX-IFX group compared with 32\% in the MTX-placebo group; and 32\%-37\% reached an ACR 70 in the MTX-IFX group compared with $21 \%$ in the MTX-placebo group. The DAS 28 score improved by $43 \%-48 \%$ in the combination therapy group and by $30 \%$ in the MTX-placebo group (St Clair et al 2004). Similar trends were found in a smaller trial, although the difference between groups did not necessarily reach significance (Quinn et al 2005). Interestingly, the ASPIRE trial revealed that ESR and CRP levels correlated with progressive joint damage only in the MTX-placebo group, suggesting that patients treated with MTX-IFX achieved radiographic benefit regardless of the effects on the clinical and biological parameters (Smolen et al 2006).

Overall, the results of the different RCTs comparing MTX-IFX with MTX alone indicate that improvements on measures of disease activity are relatively modest.

\section{Disease progression}

The true measure of disease progression in RA is generally thought to be long-term outcomes such as severe disability or surgical joint replacement. Since these outcomes occur late in the disease, measurable proxy outcomes have been developed, such as radiographic joint damage or functional disability indices. Radiographic joint damage represents the cumulative natural history of the disease in the individual patient. Many studies have shown convincingly that the level of radiographic damage of the joints is associated with long-term loss of function and long-term disability. Radiographic measures of structural joint damage are currently considered the "gold standard" for treatment efficacy studies (van der Heijde 2000). Thus, prevention or control of progressive joint damage has become a crucial goal for clinicians managing RA (ACR 2002) and has been recognized as a primary goal by the US Food and Drug Administration (Boers 1999). The most commonly used instrument to assess radiographic joint damage is a semi-quantitative scoring system known as the vdH-S score (van der Heijde 2000). The score ranges from 0 to 448 and includes an erosion score and a joint-space-narrowing score based on hand and feet plain X-rays. Because of the limited sensitivity to change of conventional X-rays, ultrasound (US) and magnetic resonance imaging (MRI) have also started to be used to assess structural joint damage progression but the imaging techniques are not yet validated for clinical trials.

Functional disability in RA is generally assessed with the Stanford Health Assessment Questionnaire (HAQ), which is a 20 item self-report questionnaire ranging from 0 to 3 . The HAQ tends to increase slowly over time in patients with RA (average of 0.03 units per year and has been shown to predict work disability, joint replacement, medical costs, and mortality (Michaud et al 2005; Wolfe et al 1998) in RA. Radiographic damage and HAQ scores correlate rather well in advanced disease (Welsing et al 2001).

Radiographic joint damage was a primary outcome in 4 out of 8 studies (the 3 redundant studies having been excluded and 1 study not reporting conventional radiologic data). All the studies showed significantly less progression on the $\mathrm{vdH}-\mathrm{S}$ score in the MTX-IFX group. The pooled results from these 4 studies including a total of 1647 patients showed a reduction in radiographic progression of $4.1 \mathrm{vdH}-\mathrm{S}$ score units $(95 \%$ CI: 3.5 ; 4.6) per year in the MTX-IFX compared with the MTX-placebo groups (Breedveld et al 2004; St Clair et al 2004; Taylor et al 2004; Goekoop-Ruiterman et al 2005; Quinn et al 2005). The protective effect of IFXMTX on radiographic damage progression was not significantly better with higher dosages of IFX $(p=0.82)$.

Three small studies examined the progression of structural damage with other means than conventional radiography (MRI follow up and joint US with power doppler). Synovitis, bone edema, and erosions were scored on MRIs of the 2 nd to the 5 th metacarpophalangial joints and total synovial thickness and vascularity assessments were scored by US Power Doppler imagery. These studies confirmed the superiority of the MTX- IFX to MTX alone in early RA (Taylor et al 2004; Quinn et al 2005; Taylor et al 2006). 
Three out of 8 studies used the functional disability (HAQ) score as an endpoint. Just as for radiographic damage progression, all 3 studies showed an advantage in the HAQ improvement for the MTX-IFX combination compared with the control group. Patients on MTX-placebo improved their HAQ scores on average by $18 \%-50 \%$, whereas patients on MTX-IFX combination improved their HAQ scores by $58 \%-80 \%$ after 1 year of follow up, depending on the studies (Breedveld et al 2004; St Clair et al 2004; GoekoopRuiterman et al 2005; Quinn et al 2005). One analysis (Smolen et al 2006) focused on the effect on employability in early RA and found a greater ability of patients treated with the IFX-MTX to keep their job, but failed to demonstrate a difference of employment rates between patients treated with or without IFX. One smaller study showed an effect on function which persisted even after IFX was stopped. The effect on functional disability in favor of the MTX-IFX was maintained 1 year after interruption of IFX (Quinn et al 2005).

\section{Safety}

Many questions concerning safety of anti-TNF agents have been raised, particularly concerning an increased risk of infections and tumors. Three studies using IFX in early RA reported treatment side effects. The BEST study (GoekoopRuiterman et al 2005), a multi-center RCT including 508 patients, compared 4 different treatment strategies and reported the side effects in each group. The first group was treated with sequential monotherapy of traditional DMARDs; the second group with a step-up combination therapy of traditional DMARDs; the third group with prednisone (quickly tapered to $7.5 \mathrm{mg} /$ day), MTX, and sulfasalazine; the fourth group with MTX-IFX. The BEST study concluded that there was no statistical significant difference in the frequency of side effects or treatment withdrawal between the 4 treatment groups. Nine out 121 patients were found to have latent tuberculosis before treatment initiation of MTX- IFX and took isoniazide before starting IFX, and none of them developed active tuberculosis. The largest study in early RA including 1049 patients (ASPIRE) reported significantly more pneumonias in patients treated with MTX-IFX than with MTX alone (2\% in the MTX- IFX group vs $0 \%$ in the placebo MTX group). The frequency of other infections (upper respiratory infections, sinusitis, pharyngitis) were similar between the MTX-IFX and MTX-placebo groups. In the same study, 4 patients, all in the MTX-IFX group, developed tuberculosis. Two of them had a negative PPD skin test before the start of IFX.
Four solid tumors in the MTX-IFX high-dose group $(6 \mathrm{mg} / \mathrm{kg})$, but none in the MTX-IFX low-dose group $(3 \mathrm{mg} / \mathrm{kg})$ or in the placebo group, were reported in the ASPIRE trial (Breedveld et al 2004; St Clair et al 2004). The BEST study reported a bladder carcinoma in the step up group and one breast cancer and one lymphoma in the prednisone, MTX, and sulfasalazine group (Goekoop-Ruiterman et al 2005), but no malignancy was observed in the MTX-IFX group. Because of limited sample sizes and duration of follow up in RCTs, definite conclusions cannot be drawn about the potential carcinogenic risk of IFX in early RA. Side effects such as heart failure have not been reported in these patients.

A meta-analysis of infectious and carcinogenic complications of anti-TNF therapy (adalimumab and infliximab) in established RA was published recently (Bongartz et al 2006). The study found a significantly increased risk for serious infections in patients treated with MTX- IFX (OR: 2; 95\% CI 1.3-3.2), but no difference between the low and high dosage of anti-TNF agents. Malignancies were found in 29 out of 3493 patients receiving anti-TNF therapy compared with only 3 patients in the group treated with non-biological DMARDs. The pooled OR for malignancy in the IFX group was of 3.3; (95\% CI 1.2-9.1) compared with the control group. However it is important to note that $92 \%$ of the tumors reported in this meta-analysis occurred in patients treated with high doses unaccepted by the FDA (Callegari et al 2006). Even though anti-TNF agents have potentially serious side effects, it is important to remember that this new class of medication appears to diminish the cardiovascular morbidity and overall mortality in RA patients (Michaud and Wolfe 2005). Thus the effect of anti-TNF agents on survival is complex and should be assessed in long-term follow up studies.

\section{Cost-effectiveness}

We found no published cost-effectiveness analyses specifically for IFX in early RA. Cost-effectiveness analyses in advanced/chronic RA have shown a potential benefit in favor of MTX-IFX in RA patients resistant to MTX (Kobelt et al 2003, 2004; Barbieri et al 2005). However some limitations of these studies need to be discussed: Firstly, the comparator groups were historical patients from the 1980s, a time when antirheumatic therapy was much less effective than that used today. Secondly, the definition of costs was very heterogeneous among the different studies (direct medical costs and indirect costs). Yet the potential benefit of early aggressive treatment on long-term disability might be of great influence on secondary or indirect costs. Cost-effective analyses comparing MTX-IFX with intensive DMARD therapy in 
early RA, including both the direct and the indirect costs, are thus still needed.

\section{Discussion}

We identified 6 clinical trials comparing the combination of MTX-IFX and MTX-placebo in early RA. These studies examined the effects of treatments on radiographic joint damage, composite disease activity measures and functional disability scores. Three studies also examined safety and no study analyzed specifically the cost-effectiveness of this new therapy in early RA. The results of these studies are in favor of IFX-MTX combination in terms of radiographic damage prevention and functional disability progression. The effect on disease activity, although significant in some studies, is less striking. One smaller study showed a beneficial effect on functional disability that persisted after the interruption of IFX therapy (Quinn et al 2005). If this result was confirmed in larger studies, the cost-effectiveness of IFX would be indisputably increased in early RA. Higher dosages of IFX used in some studies were in general not associated with a statistically significant improvement in clinical and radiological outcomes (St Clair et al 2004). Furthermore, most of the malignancies reported were in that group. Thus starting with higher dosages of IFX seems to offer no advantage in early RA and potentially increases the risk associated with this therapy.

The positive results of MTX-IFX need to be put into perspective. Indeed, only the BEST study compared MTX-IFX with another combination of traditional DMARDs and found no statistically significant difference in favor of MTX-IFX (Goekoop-Ruiterman et al 2005). Forty per cent of patients in the conservative sequential monotherapy group and step-up therapy group also obtained efficient control of the disease (Goekoop-Ruiterman et al 2005). A recent meta-analysis examined the consequences of timing of IFX initiation on therapeutic effect sizes and concluded that the benefit of biological agents are significantly larger in RA patients with longer disease durations and in patients with previous MTX failure (M Lopez-Olivo 2006). This emphasizes the fact that MTX probably remains the anchor drug for the treatment of early RA, as recommended by several therapeutic guidelines (Combe et al 2006).

Some points of this review need consideration. Firstly, only 2 large studies of IFX in early RA are published (ASPIRE and BEST) and much of the available data are based on one single trial (ASPIRE). Secondly, most of the patients included in

Table I Randomized trials of infliximab in early rheumatoid arthritis

\begin{tabular}{|c|c|c|c|c|c|c|}
\hline \multirow[b]{2}{*}{ First author } & \multirow[b]{2}{*}{$\mathbf{N}$} & \multicolumn{2}{|l|}{$\begin{array}{l}\text { At study } \\
\text { inclusion }\end{array}$} & \multicolumn{2}{|c|}{$\begin{array}{l}\text { Radiographic joint damage } \\
\text { progression in I year }\end{array}$} & \multirow[t]{2}{*}{ Secondary outcomes } \\
\hline & & $\begin{array}{l}\text { Disease } \\
\text { duration }\end{array}$ & IFX dosage & $\begin{array}{l}\text { vdH-S score } \\
\text { (IFX group) } \\
\text { (SD) }\end{array}$ & $\begin{array}{l}\text { vdH-S score } \\
\text { (MTX group) } \\
\text { (SD) }\end{array}$ & \\
\hline St Clair et al 2004 & 1049 & $<3$ years & IFX 3 mg/kg & $0.4(5.8)$ & $3.7(9.6)$ & ACR response; DAS 28 \\
\hline (ASPIRE trial) & & & IFX 6 mg/Kg & $0.5(5.6)$ & $3.7(9.6)$ & HAQ; adverse effects \\
\hline $\begin{array}{l}\text { Goekoop-Ruiterman et al } 2005 \\
\text { ( }<3 \text { years BEST trial) }\end{array}$ & 508 & $<3$ years & IFX 3-6 mg/kg & $-I .4(4)$ & $7.1(-15.4)$ & $\begin{array}{l}\text { HAQ score; adverse } \\
\text { effects }\end{array}$ \\
\hline $\begin{array}{l}\text { Breedveld et al } 2004 \\
\text { (ATTRACT sub-analysis) }\end{array}$ & 66 & $<3$ years & IFX $3 \mathrm{mg} / \mathrm{kg}$ & $0.4(-4.5)$ & $9.1(7.7)$ & $\begin{array}{l}\text { vdH-Sharp score at } 2 \\
\text { years follow up }\end{array}$ \\
\hline Taylor et al 2004 & 24 & $<3$ years & IFX $5 \mathrm{mg} / \mathrm{Kg}$ & $3.3(3.6)$ & $12.2(10.10)$ & $\begin{array}{l}\text { US with power Doppler; } \\
\text { CRP; Swollen joint count }\end{array}$ \\
\hline Quinn et al 2005 & 20 & $<$ I year & & & & $\begin{array}{l}\text { MRI scores at I year; } \\
\text { ACR response; DAS 28; } \\
\text { CRP; HAQ study }\end{array}$ \\
\hline $\begin{array}{l}\text { Smolen et al } 2006 \\
\text { (ASPIRE trial) }\end{array}$ & 1004 & $<3$ years & IFX 3-6 mg/kg & $a_{-}$ & $\mathrm{a}_{-}$ & $\begin{array}{l}\text { Employability; ACR } \\
\text { response; DAS 28; }\end{array}$ \\
\hline $\begin{array}{l}\text { Smolen et al } 2006 \\
\text { (ASPIRE trial) }\end{array}$ & 1004 & $<3$ years & IFX 3-6 mg/kg & $\mathrm{a}_{-}$ & $\mathrm{a}_{-}$ & $\begin{array}{l}\text { Correlation of CRP, ESR, } \\
\text { and disease activity with } \\
\mathrm{RX} \text { progression }\end{array}$ \\
\hline Taylor et al 2006 & 24 & $<3$ years & IFX $5 \mathrm{mg} / \mathrm{Kg}$ & $a_{-}$ & $\mathrm{a}_{-}$ & $\begin{array}{l}\text { Synovial thickness/color } \\
\text { Doppler area/2 year } \\
\text { therapy }\end{array}$ \\
\hline
\end{tabular}

${ }^{\mathrm{a} D}$ Duplicate data.

Abbreviations: ACR response, American College of Rheumatology response criteria; CRP, C-reactive protein; DAS, disease activity score; ESR, erythrocyte sedimentation rate; HAQ, Stanford Health Assessment Questionnaire; IFX, infliximab; MRI, magnetic resonance imaging; MTX, methotrexate. 
these studies had moderate to severe disease activity, which limits the generalizability to all early RA patients. Thirdly, long-term results focusing on the benefit and safety of IFX in early RA are scarce. Fourthly, data on cost-effectiveness of IFX in early RA are missing, which is a major concern considering the cost of this medication and current limitations in health care resources. Further data on the benefit of early and potentially limited anti-TNF therapy on long-term disability are needed. Recent research reported in an abstract examined the long-term frequency of sustained good clinical responses and remissions in the BEST study between a group initially treated with methotrexate and prednisone and a group initially treated with methotrexate and IFX. Patients treated with IFX and methotrexate were significantly more often in these low disease states 3 years after enrolment, despite by then receiving similar anti-rheumatic treatment (van der Kooij 2006).

Lastly, even though anti-TNF agents have potentially serious side effects, it is important to remember that this new class of medication appears to diminish the cardiovascular morbidity and overall mortality in RA patients (Michaud and Wolfe 2005). Thus the effect of anti-TNF agents on survival is complex and should be assessed in long-term follow up studies.

\section{Conclusion}

In early RA, IFX in combination with MTX is more effective than MTX alone in preventing joint damage, improving functional disability, and reducing disease activity. Nonetheless, many patients with early RA probably do not require IFX to achieve a satisfying clinical response (Boers et al 1997; Boers 1999). There is no evidence for the superiority of MTX-IFX over MTX in combination with traditional DMARDs. In our opinion, the prescription of IFX should be limited to early RA patients with clinical and biological signs of aggressive disease, such as an insufficient response to MTX alone or the presence of rapidly progressing erosions. Nonetheless, early, short-term treatment with anti-TNF might be a costeffective option if the biologic treatment can be interrupted, and needs further evaluation.

\section{References}

[ACR] American College of Rheumatology. 2002. Guidelines for the management of rheumatoid arthritis: 2002 Update. Arthritis Rheum, 46:328-46.

Arnett FC, Edworthy SM, Bloch DA, et al. 1988. The American Rheumatism Association 1987 revised criteria for the classification of rheumatoid arthritis. Arthritis Rheum, 31:315-24.

Barbieri M, Wong JB, Drummond M. 2005. The cost effectiveness of infliximab for severe treatment-resistant rheumatoid arthritis in the UK. Pharmacoeconomics, 23:607-18.
Boers M. 1999. Combination therapy in rheumatoid arthritis. Lancet, 354:952. Boers M, Verhoeven AC, Markusse HM, et al. 1997. Randomised comparison of combined step-down prednisolone, methotrexate and sulphasalazine with sulphasalazine alone in early rheumatoid arthritis. Lancet, 350:309-18.

Bongartz T, Sutton AJ, Sweeting MJ, et al. 2006. Anti-TNF antibody therapy in rheumatoid arthritis and the risk of serious infections and malignancies: systematic review and meta-analysis of rare harmful effects in randomized controlled trials. JAMA, 295:2275-85.

Breedveld FC, Emery P, Keystone E, et al. 2004. Infliximab in active early rheumatoid arthritis. Ann Rheum Dis, 63:149-55.

Callahan LF. 1998. The burden of rheumatoid arthritis: facts and figures. J Rheumatol Suppl, 53:8-12.

Callegari PE, Schaible TF, Boscia JA. 2006. LETTERS: Risk of serious infections and malignancies with anti-tnf antibody therapy in rheumatoid arthritis. JAMA, 296:2201-2202

Combe B, Landewe R, Lukas C, et al 2006. Eular recommendations for the management of early arthritis: report of a task force of the European Standing Committee for international Clinical Studies Including therapeutics (ESCISIT). Ann Rheum Dis, 66:34-45

Deeks J, Higgins J, Altman D. 2004. Analysing and presenting results. The Cochrane Reviewers' Handbook. Alderson P, Green S, Higgins J. (eds) Chichester, UK: John Wiley \& Sons Ltd. 4.2.2.

Edmonds JP, Scott DL, Furst DE, et al. 1993. Antirheumatic drugs: a proposed new classification. Arthritis Rheum, 36:336-9.

Felson DT, et al 1995. American college of rheumatology preliminary definition of improvement in rheumatoid arthritis. Arthritis Rheum, 38:727-35.

Felts W, Yelin E. 1989. The economic impact of the rheumatic diseases in the United States. J Rheumatol, 16:867-84.

Finckh A, Mugica van Herckenrode C, Liang M, et al. 2006. Long-term impact of early aggressive treatment of rheumatoid arthritis. A metaanalysis. Arthritis Rheum, 55. In press.

Goekoop-Ruiterman YP, de Vries-Bouwstra JK, Allaart CF, et al. 2005. Clinical and radiographic outcomes of four different treatment strategies in patients with early rheumatoid arthritis (the BeSt study):a randomized, controlled trial. Arthritis Rheum, 52:3381-90.

Graudal N, Tarp U, Jurik AG, et al. 2000. Inflammatory patterns in rheumatoid arthritis estimated by the number of swollen and tender joints, the erythrocyte sedimentation rate, and hemoglobin: longterm course and association to radiographic progression. J Rheumatol, 27:47-57.

Jansen LM, van der Horst-Bruinsma IE, van Schaardenburg D, et al. 2001. Predictors of radiographic joint damage in patients with early rheumatoid arthritis. Ann Rheum Dis, 60:924-7.

Kobelt G, Eberhardt K, Geborek P 2004. TNF inhibitors in the treatment of rheumatoid arthritis in clinical practice: costs and outcomes in a follow up study of patients with RA treated with etanercept or infliximab in southern Sweden. Ann Rheum Dis, 63:4-10.

Kobelt G, Jonsson L, Young A, et al. 2003. The cost-effectiveness of infliximab (Remicade) in the treatment of rheumatoid arthritis in Sweden and the United Kingdom based on the ATTRACT study. Rheumatology (Oxford), 42:326-35.

M Lopez-Olivo ZO, Pak CH. 2006. A meta-analysis on the timing of therapeutic introduction of infliximab (IFX) and etanercept (ETN). Annual European Congress of Rheumatology, Amsterdam, Ann Rheum Dis, 65(Suppl II):(FRI0141), p329.

Michaud K, Wolfe F. 2005. Reduced mortality among RA patients treated with anti-TNF therapy and methotrexate. EULAR Vienna, Dis. Ann Rheum Dis, 64(Suppl III):87.

Pincus T. 1998. Aggressive treatment of early rheumatoid arthritis to prevent joint damage. Bull Rheum Dis, 47:2-7.

Quinn MA, Conaghan PG, O'Connor PJ, et al. 2005. Very early treatment with infliximab in addition to methotrexate in early, poor-prognosis rheumatoid arthritis reduces magnetic resonance imaging evidence of synovitis and damage, with sustained benefit after infliximab withdrawal:results from a twelve-month randomized, double-blind, placebo-controlled trial. Arthritis Rheum, 52:27-35. 
Schering-Plough Corporation. 2006. Remicade (infliximab) gains Australian approval for treatment of early rheumatoid arthritis [online]. URL: www.News-Medical.Net.

Scott DL, Smith C, Kingsley G. 2003. Joint damage and disability in rheumatoid arthritis:an updated systematic review. Clin Exp Rheumatol, 21(5 Suppl 31):S20-7.

Silman AJ. 2001. Rheumatoid arthritis. epidemiology of the rheumatic diseases. Silman AJ, Hochberg MC (eds). Oxford: Oxford University Press. p 31-71.

Smolen JS, Han C, van der Heijde D, et al. 2006. Infliximab treatment maintains employability in patients with early rheumatoid arthritis. Arthritis Rheum, 54:716-22.

Smolen JS, van der Heijde DM, St Clair EW, et al. 2006. Predictors of joint damage in patients with early rheumatoid arthritis treated with high-dose methotrexate with or without concomitant infliximab:results from the ASPIRE trial. Arthritis Rheum, 54:702-10.

St Clair EW, van der Heijde DM, Smolen JS, et al. 2004. Combination of infliximab and methotrexate therapy for early rheumatoid arthritis: a randomized, controlled trial. Arthritis Rheum, 50:3432-43.

Taylor PC, Steuer A, Gruber J, et al. 2004. Comparison of ultrasonographic assessment of synovitis and joint vascularity with radiographic evaluation in a randomized, placebo-controlled study of infliximab therapy in early rheumatoid arthritis. Arthritis Rheum, 50:1107-16.
Taylor PC, Steuer A, Gruber J, et al. 2006. Ultrasonographic and radiographic results from a two-year controlled trial of immediate or oneyear-delayed addition of infliximab to ongoing methotrexate therapy in patients with erosive early rheumatoid arthritis. Arthritis Rheum, 54:47-53.

van der Heijde D. 2000. How to read radiographs according to the Sharp/van der Heijde method. J Rheumatol, 27:261-3.

van Der Kooij SM. 2006. Induction of remission in patients with early rheumatoid arthritis (RA) initially treated with either prednisone or infliximab combination therapy [abstract]. Arthritis Rheum 54 (Suppl): S302 (abstract 658).

Welsing PM, van Gestel AM, Swinkels HL, et al. 2001. The relationship between disease activity, joint destruction, and functional capacity over the course of rheumatoid arthritis. Arthritis Rheum, 44:2009-17.

Wilske KR, Healey LA. 1989. Remodeling the pyramid - a concept whose time has come. J Rheumatol, 16:565-7.

Wolfe F, Hawley DJ. 1998. The longterm outcomes of rheumatoid arthritis: Work disability:a prospective 18 year study of 823 patients. $J$ Rheumatol, 25:2108-17.

Young A, Dixey J, Kulinskaya E, et al. 2002. Which patients stop working because of rheumatoid arthritis? Results of five years' follow up in 732 patients from the Early RA Study (ERAS). Ann Rheum Dis, 61:335-40. 
